\title{
Particle swarm optimisation-based optimal photovoltaic system of hourly output power dispatch using lithium-ion batteries
}

\author{
M. A. Jusoh and M. Z. Daud* \\ School of Ocean Engineering, Universiti Malaysia Terengganu \\ 21030 Kuala Nerus, Terengganu, Malaysia \\ *Email: zalani@umt.edu.my
}

\begin{abstract}
Power fluctuation of a grid-connected photovoltaic (PV) system can give unnecessary stress and impacts to the point where it is connected. To minimise the output power fluctuation, a hybrid PV system and battery energy storage (BES) system can be developed and controlled so that the total output of the system is smoothed out and dispatched on an hourly basis to the electricity grid. This paper presents an improved mitigation strategy using Lithium-ion (Li-ion) BES namely the State-of-Charge Feedback (SOC-FB) controller with the goal of minimising the output power fluctuations of the PV system while ensuring the Li-ion BES operational constraints are regulated at the desired range. To optimally control the SOC-FB controller, Particle Swarm Optimisation algorithm was used to obtain an optimal dispatch of the PV/BES system while maintaining the BES operational constraints at the desired range. A simulation study was carried out using the MATLAB/Simulink software with the simulation results showing the acceptable performance of the proposed hybrid PV/BES hourly power dispatch control strategy. The simulation results also showed that the optimal size of BES can be reduced up to $1.6 \%$ using Li-ion battery. This indicates the reasonable performance of the Li-ion batteries especially when it comes to mitigating the power fluctuations of the PV system output.
\end{abstract}

Keywords: Renewable energy dispatch; photovoltaic system; particle swarm optimisation, power fluctuation; battery energy storage.

\section{INTRODUCTION}

Solar photovoltaic (PV) energy source is becoming a more attractive source of alternative energy to cater for the increasing fuel cost and environmental pollutions. This type of renewable energy system is very feasible and it is an alternative solution to energy issues because of its sustainability, needs less maintenance and more importantly produces little or no waste products. Nevertheless, the Solar PV energy is unpredictable and inconsistent because it often relies on weather and environmental conditions which as a result would impose adverse impacts on power quality such as power fluctuation at the point where it is connected [1]. High power fluctuations injected to the utility grid cause unnecessary voltage rise and deviations of voltage and frequency from their nominal values which may affect sensitive equipment in manufacturing sectors [2]. These problems are some of the obstacles to the efforts of increasing the penetration level of PV power in the grid system. Therefore, there is a need to control the injected power from solar PV to the grid system like any other conventional generator such as the hydropower plant. 
The hybrid system that includes solar PV panels and energy storage (ES) is best suited to handle the issues of power fluctuation. The ES, especially battery energy storage (BES) system, can offer flexible energy management that can help to reduce power fluctuation from renewable energy source systems [3]. The development of BES for power system application is rapidly growing in improving battery performances, especially for Lithium-ion (Li-ion) battery type. The batteries used in power system applications are commonly deep cycle battery types with efficiencies of 70\%-80\% and energy capacity range of 17 to $40 \mathrm{MWh}$ [4-6]. Li-ion batteries are suitable for a hybrid renewable energy system compared to Lead Acid (LA) batteries because of their excellent characteristics such as high energy capacity, high efficiency, low maintenance, long life cycle, and environmentally-friendly [7, 8]. Comparison of Li-ion and LA battery characteristics is as shown in Table 1 . Li-ion batteries have been widely used in large scale practical installations such as a hybrid renewable energy power plant that consists of 100-MW wind farm, a 40-MW PV farm, and 14-MW/63-MWh Li-ion battery in Zhangbei, Hebei, China [3]. They have also been installed in West Virginia, USA, for the Laurel mountain wind project [9]. A $32 \mathrm{MW} \mathrm{Li-ion} \mathrm{battery} \mathrm{integrated} \mathrm{with} \mathrm{the} \mathrm{Laurel}$ mountain $98 \mathrm{MW}$ wind farm has been used to manage the output fluctuations. Other than that, in the Tehachapi wind energy project in USA, Li-ion battery has been used to integrate with wind farm for frequency regulation and ramp management [9].

Table 1. Comparison between Li-ion battery and LA battery $[9,10]$.

\begin{tabular}{|c|c|c|c|c|}
\hline \multirow[t]{2}{*}{ Parameters (Unit) } & \multicolumn{3}{|c|}{ Li-ion } & \multirow[t]{2}{*}{ LA } \\
\hline & Cobalt & Manganese & Phosphate & \\
\hline Specific energy density $(\mathrm{Wh} / \mathrm{kg})$ & $\begin{array}{c}150- \\
190\end{array}$ & $100-135$ & $90-120$ & $30-50$ \\
\hline Fast charge time (hour) & $2-4$ & 1 or less & 1 or less & $8-16$ \\
\hline Charge temperature $\left({ }^{\circ} \mathrm{C}\right)$ & & 0 to 45 & & -20 to 50 \\
\hline Discharge temperature $\left({ }^{\circ} \mathrm{C}\right)$ & & -20 to 60 & & -20 to 50 \\
\hline Maintenance requirement (month) & & Not Requir & & $3-6$ \\
\hline Safety requirements & Prote & tion circuit $\mathrm{r}$ & andatory & $\begin{array}{c}\text { Thermally } \\
\text { stable }\end{array}$ \\
\hline In use since (year) & 1991 & 1996 & 1999 & Late $1800 \mathrm{~s}$ \\
\hline Toxicity & & Low & & Very high \\
\hline Maintenance costs (\%) & & None & & $10 \%$ \\
\hline Efficiency $(\%)$ & & $97 \%$ & & $75 \%$ \\
\hline Replacement timeframe (year) & & $5-7$ & & $1.5-2$ \\
\hline
\end{tabular}

Recently, there are many research works that concentrate on using BES for power fluctuation mitigation of renewable energy [11-18]. A 1 MW LA battery was used as BES to mitigate the output fluctuation from $1 \mathrm{MW}$ PV system [11]. The real-time ramp rate control scheme was proposed to monitor the real power from the PV generator and command the BES to charge and discharge the power to the system during power fluctuation mitigation process. In [12], the control scheme based on fuzzy logic and wavelet transform was proposed for reducing output power fluctuations of hybrid PV/Wind/BES power generation. The operational constraints of BES were managed using the membership functions of fuzzy logic. From the simulations results, the output power of hybrid PV/Wind/BES was properly managed by the fuzzy logic controller. A Kalman filter combined with the fuzzy logic control method was proposed in [13] to 
control $100 \mathrm{kWh} \mathrm{Li-ion} \mathrm{BES} \mathrm{system} \mathrm{for} \mathrm{smoothing} \mathrm{the} \mathrm{output} \mathrm{power} \mathrm{fluctuation} \mathrm{of} \mathrm{wind}$ energy source. A dual layer optimisation-based strategy for mitigating wind farm fluctuations was proposed in [14]. The power allocation layer was optimised by using PSO algorithm while the energy management layer was optimised by using mixed-integer quadratic programming (MIQP). In [15], a ramp rate control strategy used $12 \mathrm{kWh}$ LABES system for mitigating the output power fluctuation of PV energy source. The proposed strategy was able to control the desired ramp-rate independent of the past history of the PV panel output.

Besides that, there are also several researchers who focused on the output power fluctuation mitigation and hourly power dispatch of renewable energy sources [19-23]. For example, in [19], the authors proposed the optimisation-based control strategy for 500Ah LA-BES system to minimise the output power fluctuation from 1.2 MW wind farm and dispatching on an hourly basis. A one-day ahead forecasted data of wind output power used this control strategy. Based on the hourly concept in [19], the rules-based control strategy was proposed in [20]. The control strategy effectively smoothed out the power fluctuation of wind energy sources and there were fewer requirements of computational power and active memory compared to the control strategy in [19]. Apart from that, a $300 \mathrm{kWh}$ VRLA battery with SOC-FB control strategy has been introduced in [21] to smooth out power fluctuation from PV energy sources. The control strategy regulated the state-of-charge (SOC) of the BES according to the desired operational constraints of BES and the output of PV system was dispatched to the grid system on an hourly basis. To optimally dispatch the PV system output and BES constraints, the control strategy was optimised using heuristic optimisation. The proposed control strategy smoothed out the power fluctuation at a high efficiency of up to $90 \%$. The authors also proposed different algorithms such as Gravitational Search Algorithm (GSA) and PSO in order to optimise the parameters of the control scheme [22]. PSO is one of the greatest heuristic methods due to the advantages of its simplicity and easy implementation [24]. The PSO algorithm is widely used as function optimisation, model classification, machine study, neutral network training, the signal procession, vague system control, and automatic adaptation control $[24,25]$. The PSO algorithm has also been demonstrated and successfully applied to tracking and optimising dynamic systems of the solar PV system. In [26], PSO algorithm was used in maximum power point tracking (MPPT) to track the maximum power point (MPP) located during extreme environmental conditions; e.g., large fluctuations of insolation and partial shading condition. Besides that, the authors in [27] proposed the PSO algorithm method to determine the optimum size of hybrid PV, wind, and BES system. Based on the literature reviews, only a few research works concentrated on the mitigation of output power fluctuation and hourly power dispatch of PV systems using Li-ion battery. The mitigation of output power fluctuation and hourly power dispatch of PV using Li-ion battery imply high additional costs due to the expensive prices of the large scale Li-ion BES. Therefore, extensive study is necessary to investigate a cost effective and efficient method to smooth power fluctuation. The objective of this paper is to investigate the performance of Li-ion battery compared to LA battery in mitigating and dispatching output power fluctuation of solar PV in an hourly basis.

This paper presents an improved control scheme for a hybrid PV/BES system to dispatch out the output power from the PV system to the utility grid. The Li-ion battery model equations were implemented using MATLAB/Simulink blocks. The developed Liion battery model was validated with the real Li-ion battery data. Then, the developed Liion battery model was used with the SOC-FB controller for power fluctuation mitigation 
strategy. Optimisation was performed using PSO to obtain an optimum set of SOC-FB control parameters as well as the adequate size of Li-ion batteries used.

\section{METHODS AND MATERIALS}

\section{Development of the SOC-FB control scheme}

The SOC-FB control scheme has been proposed in [21] for power smoothing and hourly dispatch of hybrid PV/BES system. The objective of the controller was to generate the BES reference power $\left(P_{B E S, r e f}\right)$ for PV power dispatch. As shown in Error! Reference source not found., $\mathrm{PV}$ array output $\left(P_{P V}\right)$, power set-point output $\left(P_{S E T}\right)$ and remaining energy level $(R E L)$ were used as inputs in generating the reference power. $P_{S E T}$ is the calculated average of $P_{P V}$ output for next hour with forecast accuracy of $90 \%$ and it was used as reference for BES charging/discharging operation. The REL represents the SOC level of BES that can be obtained from Eq. (1).

$$
R E L=C_{B E S}-\int P_{B E S} d t
$$

where $C_{B E S}$ is the BES capacity and $P_{B E S}$ is the BES output power. REL becomes the feedback signal to the controller and the variation of $R E L$ (i.e. SOC) depends on the control parameters, namely, the SOC time constant, $T_{S O C}$ and the SOC margin rate denoted as $M_{S O C}$ as shown in Figure 1. The offset signal (offset $=T_{S O C} \times M_{S O C}$ ) was applied to allow a user to specify the percentage of BES energy for regulation. For example, if a maximum of $70 \%$ of BES rated capacity was to be used during regulation, $M_{S O C}$ was set to 0.7 in per unit value.

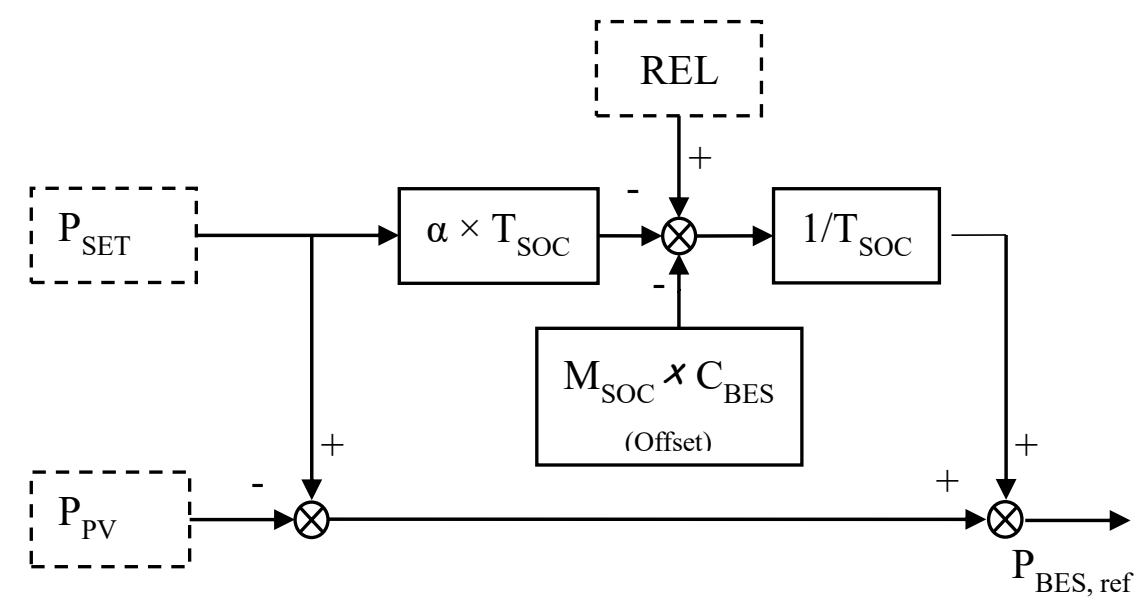

Figure 1. Block diagram of the SOC-FB controller [21].

However, in achieving a perfect dispatch with the specified operational constraints, the value of $M_{S O C}$ depended on $T_{S O C}$ and BES capacity. Besides that, $\alpha \times T_{S O C}$ signal was applied to $P_{S E T}$ to ensure the target output variation remained within the BES capacity. This signal will adjust the BES output to the charging/discharging direction based on $R E L$ level. The coefficient of $T_{S O C}, \alpha$ was defined using Eq. (2), where $P_{P V}$, rated is the rated capacity of the PV system. 


$$
\alpha=\frac{C_{B E S}\left(1-2 M_{S O C}\right)}{T_{S O C} \times P_{P V, \text { rated }}}
$$

\section{Development of Li-ion Battery Model}

The SOC-FB controller in [21] was developed for power smoothing and hourly dispatch of hybrid PV/BES system output and LA battery has been used as BES. In this work, some improvements have been made where the LA battery was replaced with the Li-ion battery as the BES system. The modification was intended to investigate the performance of Li-ion BES with the SOC-FB controller for output power fluctuation mitigation. Battery simulation is a frequently used technique to reduce cost and time during the design and development phase, especially for hybrid application systems [28]. The simulation process provides essential benefits with no expensive test and measurement equipment required. In order to design good behaviour of battery, model-based power electronics for hybrid PV/BES, several parameters such as SOC, terminal voltage, cell temperature, internal resistance and other non-linear factors were required. For modelling the battery model, the dynamic battery model developed in [29, 30] was used. Battery model has been derived based on Eq. (3) and (4).

$$
\begin{gathered}
V_{B a t}=E_{B a t}-R_{\mathrm{int}} I_{B a t} \\
S O C=100\left(\frac{\int I_{B a t} d t}{Q}\right)
\end{gathered}
$$

where $V_{B a t}$ is the battery voltage, $R_{\text {int }}$ is the battery internal resistance, $I_{B a t}$ is the battery current, $Q$ is the cell capacity and $E_{B a t}$ is the battery electromotive force defined using Eq. (5) and (6):

$$
\begin{gathered}
E_{\text {Bat_disc }}=E_{0}-\left[K\left(\frac{Q}{Q-i t}\right) i^{*}\right]-\left[K\left(\frac{Q}{Q-i t}\right) i t\right]+A e^{(-B)(i t)} \\
E_{\text {Bat_charg }}=E_{0}-\left[K\left(\frac{Q}{i t-0.1 Q}\right) i^{*}\right]-\left[K\left(\frac{Q}{Q-i t}\right) i t\right]+A e^{(-B)(i t)}
\end{gathered}
$$

where $E_{\text {Bat_disc }}$ and $E_{\text {Bat_charg }}$ are the battery electromotive force during charge and discharge, $E_{0}$ is the battery open-circuit voltage, $K$ is the polarisation constant/polarisation resistance, $i t=\int I_{B a t} d t$ is the actual battery current, $i^{*}$ is the filtered current, $A$ is the exponential zone voltage and $B$ is the exponential zone time constant inverse.

Table 2 illustrates the needed parameters of the Li-ion battery model development. All of the parameters mentioned in Table 2 can be extracted from the manufacturer's typical discharge curve data following the procedures in [29]. In this work, the typical discharge curve of A123 Li-ion ANR26650M1 battery model was used. The parameters in Table 3 were used to determine the value of $\mathrm{A}$ and $\mathrm{B}$ in the battery equation. For the battery parameters, it was assumed that the internal resistance and nominal capacity were constant, there were no self-discharge, no memory effect on the parameters and no environmental considerations. From the cell battery model, a BES model can be constructed by the series $n_{s}$ and parallel $n_{p}$ combinations of battery cell, in which power was assumed to be consistently distributed among cells as described in Eq. (7), where $n_{s}$ 
determines the total output of terminal voltage, and $n_{p}$ characterises the capacity or total size of a battery bank in kilowatt hours.

$$
P_{B E S}=V_{B E S} \times I_{B E S}=n_{s} V_{B a t}-n_{p} I_{B a t}
$$

The battery model in Figure 2 was constructed based on the battery equations and implemented in MATLAB/Simulink. The battery model was represented in simulation function blocks for easier presentation and further modification to the battery model, for example battery model with temperature effects, memory effects and other factors. The mathematical equations of battery model were constructed using function block in the MATLAB/Simulink, while the Li-ion battery parameters were implemented in the MATLAB/M-file before the data were added to the MATLAB/Workspace. The modelled Li-ion battery in the simulation was validated based on the typical discharge characteristics curve of A123 Li-ion ANR26650M1 from the manufacturer following the procedures in [29]. During validation, the constant battery currents were set at 1A, 10A, and $30 \mathrm{~A}$ as illustrated in Figure 2. The discharge characteristic curves of the developed Li-ion battery model were compared with the typical discharge characteristics curve of A123 Li-ion ANR26650M1.

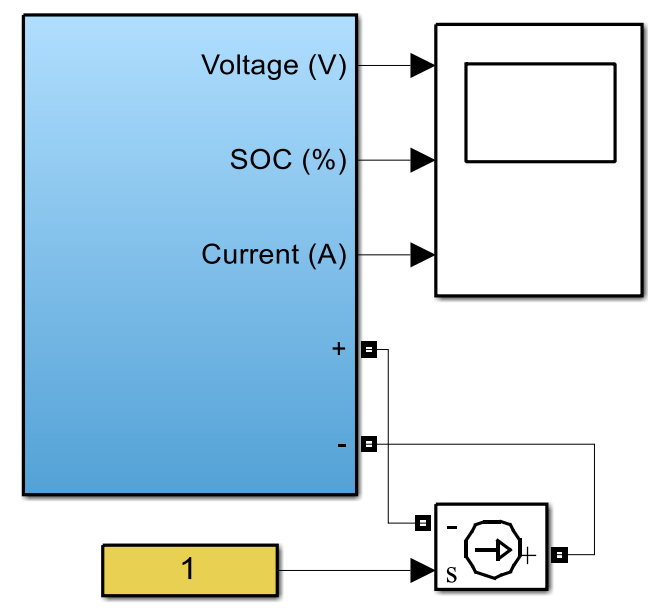

Figure 2. Developed Li-ion battery model.

\section{Optimisation of Control Parameters}

The objective of optimisation of SOC-FB controller was to minimise the deviation between $P_{S E T}$ and $P_{P V}$ so that the $P_{T O T A L}$ output followed the $P_{S E T}$ curve. To minimise the deviation, the objective function has been determined based on Eq. (8):

$$
O F(x)=\min \left\lfloor\int\left(P_{S E T}(t)-P_{\text {TOTAL }}(t)\right)^{2} d t\right\rfloor
$$

where vector $x$ (see Figure 3 ) represents the control parameter $\left(M_{S O C}, T_{S O C}\right.$ and $\left.C_{B E S}\right)$ for SOC-FB controller. The control parameters provided the optimal values based on the specified constraints for SOC-FB controller based on Eq. (9)-(11): 

batteries

$$
\begin{gathered}
S O C_{\text {min }} \leq S O C \leq S O C_{\text {max }} \\
I_{B E S, \text { min }} \leq I_{B E S} \leq I_{B E S, \max } \\
V_{B E S, \text { min }} \leq V_{B E S} \leq V_{B E S, \max }
\end{gathered}
$$

where $S O C_{\min }$ and $S O C_{\max }$ are the minimum and maximum ranges for SOC. The minimum and maximum SOC were set to $30 \%$ to $90 \%$ (0.3 to 0.9 in per unit) of battery capacity. $I_{B E S, \min }$ and $I_{B E S, \max }$ represent the minimum and maximum discharge currents that have been limited to $\pm 1 \times C_{B E S}$ ampere or $\pm 0.5 \mathrm{kA}$. $V_{B E S, \min }$ and $V_{B E S, \max }$ are the minimum and maximum BES operation voltages. In this study, terminal voltage was assumed to be 0.6 $\mathrm{kV}$ and should not exceed the minimum cut-off voltage of $0.465 \mathrm{kV}$. The SOC of the battery should be controlled within the proper range and the charging/discharging power was limited for the safety and efficiency issues of the battery operation [31].

Table 2. Extracted Li- ion battery parameters.

\begin{tabular}{lcc}
\hline Parameters (unit) & Li-ion & Remarks \\
\hline Nominal voltage $(\mathrm{V})$ & 3.22 & $V_{\text {nom }}$ \\
Nominal capacity $(\mathrm{Ah})$ & 2.08 & $Q_{\text {nom }}$ \\
Internal resistance $(\Omega)$ & 0.014 & $R_{\text {int }}$ \\
Polarisation constant & 0.00790 & $K$ \\
Rated capacity $(\mathrm{Ah})$ & 2.3 & $Q_{\text {rated }}$ \\
Maximum capacity $(\mathrm{Ah})$ & 2.3 & $Q_{\max }$ \\
Fully charged voltage $(\mathrm{V})$ & 3.748 & $V_{\max }$ \\
Exponential voltage $(\mathrm{V})$ & 3.4748 & $V_{\text {exp }}$ \\
Exponential capacity $(\mathrm{Ah})$ & 0.113 & $Q_{\exp }$ \\
\hline
\end{tabular}

MATLAB/Simulink model

MATLAB/M-file

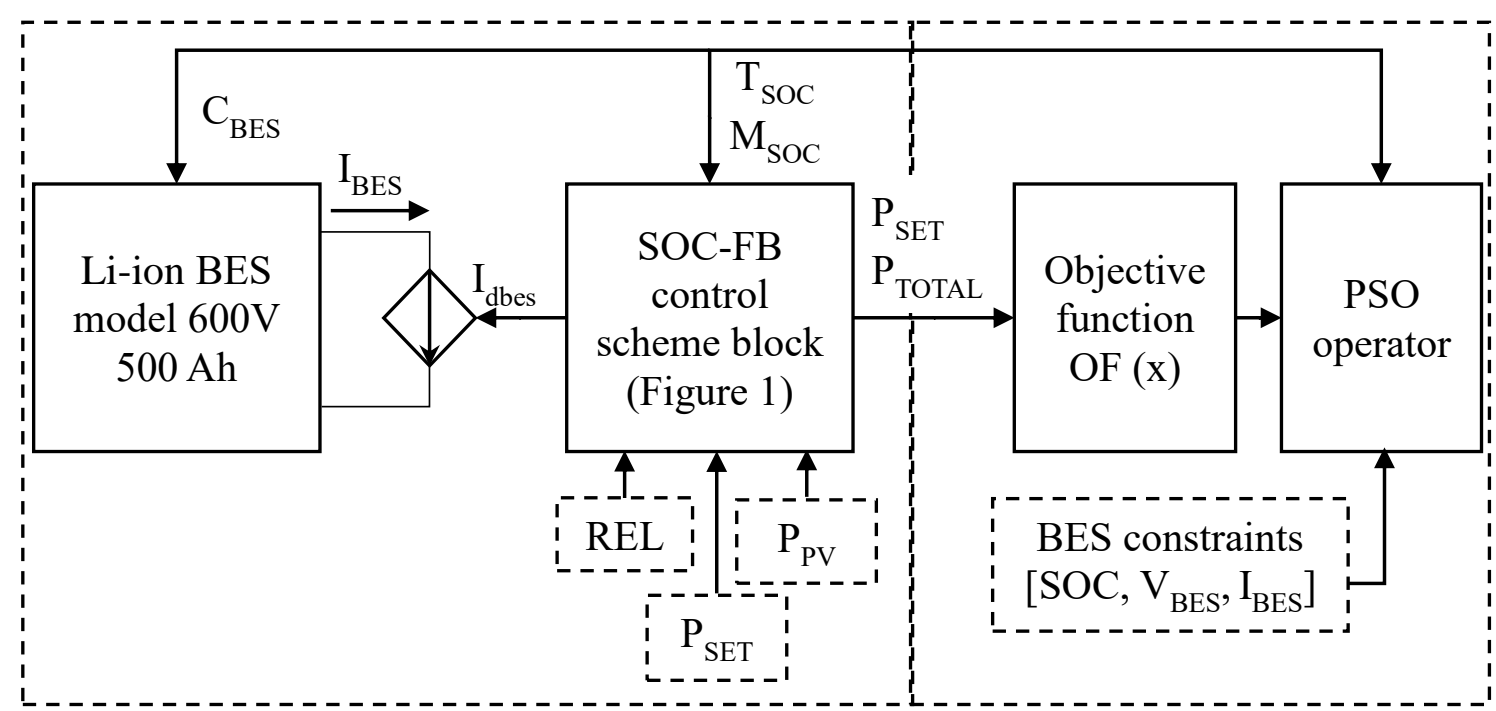

Figure 3. Generalised simulation block diagram for the evaluation of the PSO-based optimal control parameters for the BES SOC-FB control scheme. 
In order to find the optimal parameters of BES and SOC-FB controller, the optimisation approach was used based on PSO. Figure 3 depicts the complete process of simulation to evaluate the control parameters of Li-ion BES model using PSO. Based on Figure 3, BES model and SOC-FB controller in MATLAB/Simulink were linked to PSO algorithm in MATLAB/M-file and the simulation processes were running simultaneously. During the simulation, the objective function; i.e. the minimum error between $P_{S E T}$ and $P_{\text {TOTAL }}$ was evaluated by PSO and the optimal parameters of BES based on the minimum error were determined. The flowchart of BES parameters optimisation processes using PSO is presented in Figure 4. The process started with randomly setting the initial population that contained the control parameters, $M_{S O C}, T_{S O C}$ and $C_{B E S}$. The performance of the created initial values was evaluated by using fitness function in Eq. (8) and recorded in MATLAB workspace. The process of determining the best parameter values was terminated when the parameter values met the optimal criterion. The detailed processes may be referred to in [21].

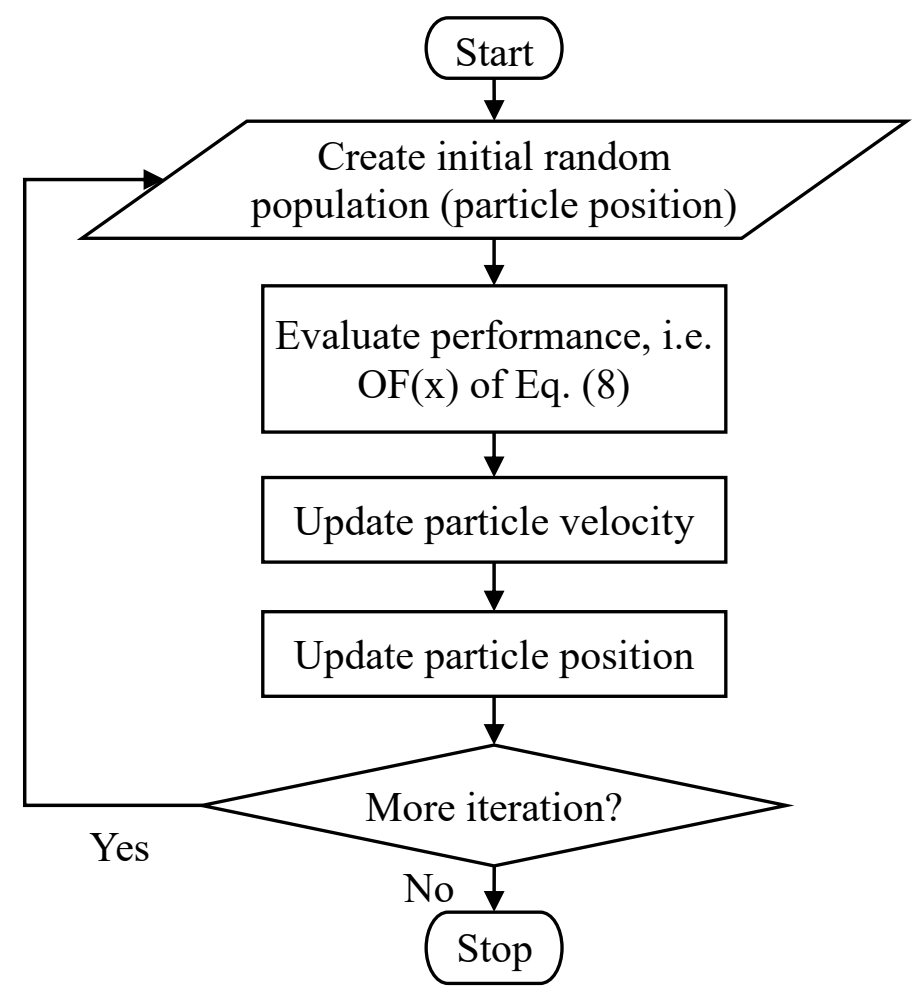

Figure 4. Flowchart of the parametric optimisation processes for PSO.

\section{RESULTS AND DISCUSSION}

This section presents the results from the simulation. Initially, the Li-ion battery model is presented and then followed by Li-ion battery model validation. Later, comparison of the simulation results with the previous works is presented.

\section{Input data for SOC-FB controller}

$P_{P V}$ and $P_{S E T}$ were used as input data in SOC-FB controller simulation. Figure 5 shows the average daily $P_{P V}$ data for 1.2 MW PV system which were analysed from the Malaysia historical radiation and temperature data [1]. The PV output data were set from 7 am to 7 
pm. From the data, the PV fluctuations mostly occurred in the afternoon, normally between $11 \mathrm{AM}$ to $3 \mathrm{PM}$ when the intermittent clouds were mostly formed. The $P_{P V}$ profile data were assumed to have power loss through the converter at approximately $5 \%$ and the data were sampled at one-minute time's step. $P_{S E T}$ was calculated from the hourly average of $P_{P V}$ values with $10 \%$ added mean absolute error (MAE) noise data to represent the forecast accuracy of the PV output-forecasting model. To minimise the output power ramp of PV system, the rate limiter was included with value $\pm 0.03 \mathrm{MW} / \mathrm{min}$ applied based on the recommendation in [20]. Limiting the power ramp in the $P_{S E T}$ can avoid overshooting during the $P_{S E T}$ changes.

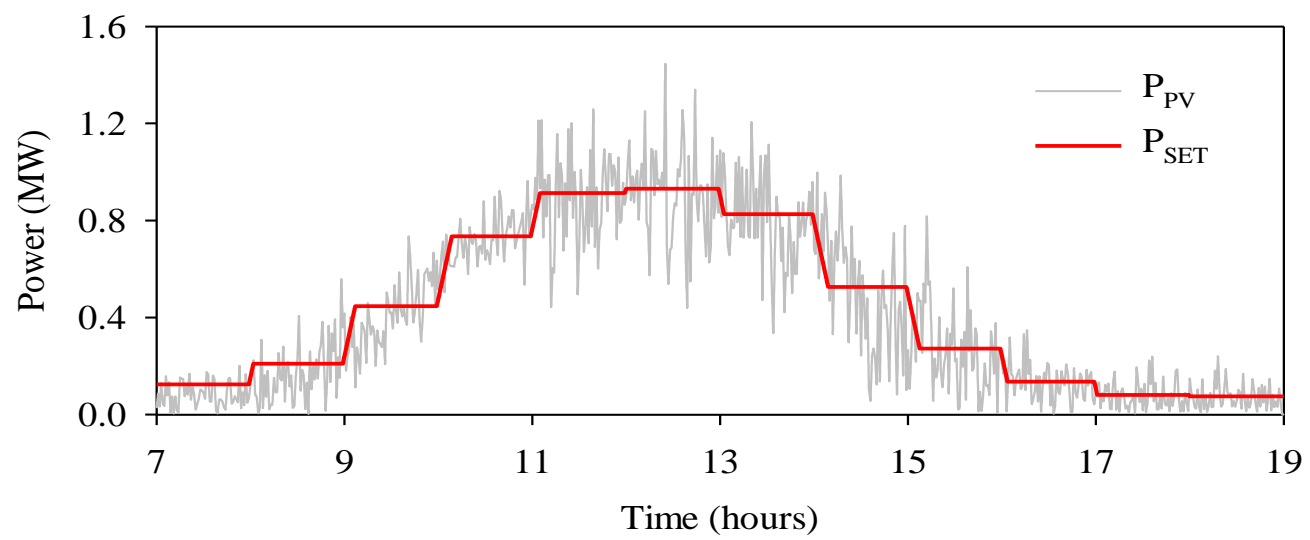

Figure 5. Average daily $P_{P V}$ data for a 1.2 MW PV system and the corresponding $P_{S E T}$ value.

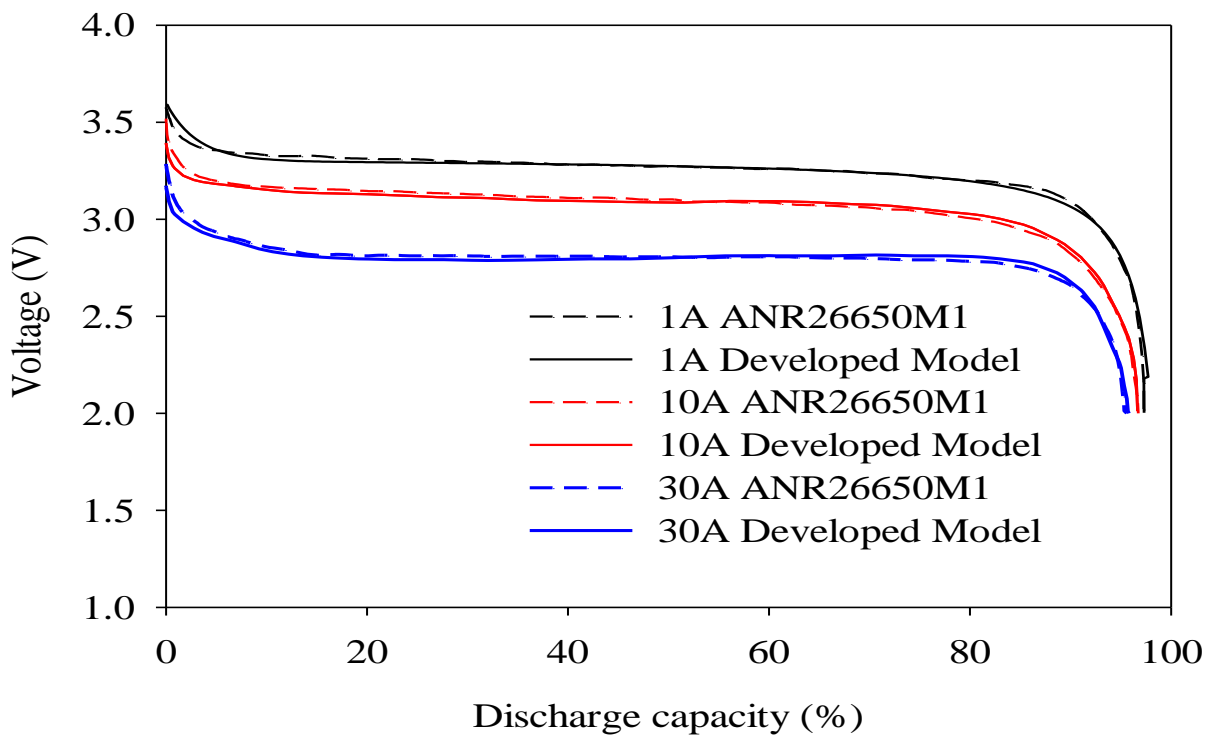

Figure 6. Validation of the discharge characteristics of the developed Li-ion battery model.

\section{The Li-ion Battery Model Validation}

The developed Li-ion battery model has been simulated to verify the validity of the model while the validation results of Li-ion battery model are as shown in Figure 6. Based on the validation results, it was observed that the discharge characteristic curves of the 
developed Li-ion model matched very well with the typical discharge characteristic curves of A123 Li-ion ANR26650M1. The accuracy of the developed model depended on the precision of the extracted data from the typical discharge curves.

\section{Comparison of SOC-FB controller Simulation Results}

From the simulation, the optimal control parameters from the PSO optimisation have been obtained and summarised in Table 3. The results of the convergence criteria using PSO are as shown in Figure 7, which shows that the optimal parameters have been obtained after 9 iterations. The optimal control parameters of Li-ion battery were compared to the optimal control parameters of LA battery from a previous work by [22]. From Table 3, the optimal capacity of Li-ion battery was 479 Ah while the optimal capacity of LA battery was $487 \mathrm{Ah}$. This showed that the capacity of Li-ion was $1.6 \%$ smaller than LA battery. The reduced capacity of BES was due to the high density characteristics of the Li-ion battery compared to the LA battery [10]. The types and the capacity size of the BES will influence the total cost of the BES. In fact, the initial cost was still much higher for Li-ion than for LA battery. However, the cost per cycle can be less for Li-ion battery compared to LA battery if their lifespans were considered [10]. This indicated that the cost of Li-ion battery was more convenient compared to the LA battery. Besides that, in terms of SOC, the result showed that the maximum SOC of Li-ion battery was up to $64 \%$ of the total BES capacity, while the maximum SOC of LA battery was $70 \%$. This reduction was due to the high efficiency and fast charge and discharge characteristics of Li-ion battery [10].

Table 3. Comparison of results of the optimal SOC-FB control performances for Li-ion and LA battery.

\begin{tabular}{llll}
\hline \multirow{2}{*}{ Parameters (Unit) } & \multirow{2}{*}{ Initial value/range } & \multicolumn{2}{c}{ Battery Types } \\
\cline { 3 - 4 } & & Li-ion & LA [22] \\
\hline SOC time constant (h) & $0.10 \leq T_{S O C} \leq 0.75$ & 0.7492 & 0.743 \\
SOC margin rate (p.u) & $0.38 \leq M_{\text {SOC }} \leq 0.75$ & 0.5784 & 0.576 \\
BES capacity (Ah) & $450 \leq C_{B E S} \leq 500$ & 479 & 487 \\
OF(x) & & 13.29 & 17.07 \\
Elapsed time (s) & - & 2876.19 & 4958 \\
PV capacity (MW) & - & 1.2 & 1.2 \\
Forecast accuracy of PSET (MAE in \%) & 10 & 10 & 10 \\
Terminal voltage (kV) & $600 \pm 20 \%$ & Max $=$ & Max $=$ \\
& & 0.698 & 0.674 \\
& & Min $=$ & Min $=$ \\
State of charge $(\%)$ & Max 70\% of total & 0.638 & 0.518 \\
Current $(\mathrm{kA})$ & capacity & & $70 \%$ \\
& Max $\pm 1 x C_{B E S}$ & \pm 0.479 & \pm 0.487 \\
\hline
\end{tabular}

Besides that, the simulation results are also shown graphically in Figure 8, which summarises the output power dispatch curve, SOC, BES voltage, and current profiles of the PV/BES system. During the optimal condition, all BES parameter constraints were satisfied and the results are shown in Figure 8(A)-8(D). Figure 8(A) shows the best output power dispatch profile based on the optimal set of parameters obtained by using PSO. It was seen that the $P_{\text {TOTAL }}$ injected to the grid system followed the desired $P_{S E T}$ perfectly 
most of the time. Based on the results in Table 3, the optimal OF (x) value of Li-ion battery was smaller than the optimal OF (x) of LA battery. These results proved that Liion battery was more efficient in mitigating output power fluctuation compared to the LA battery.

(A)

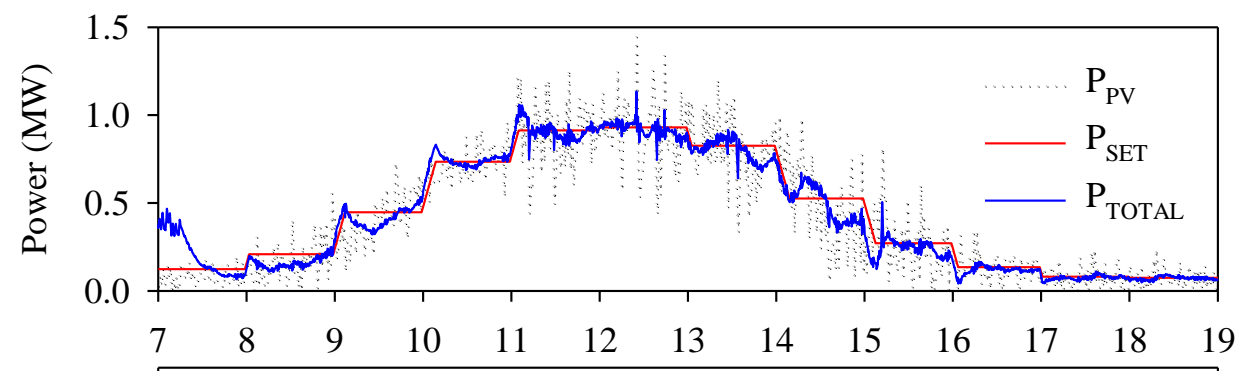

(B)

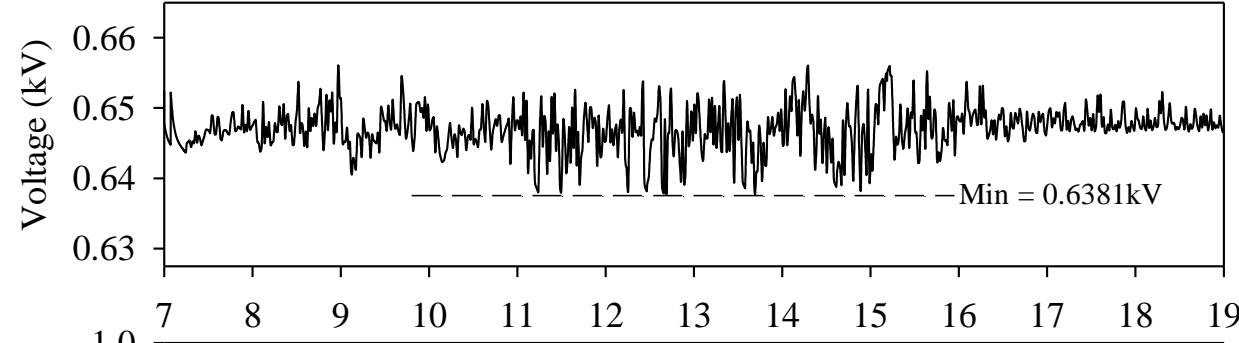

(C)

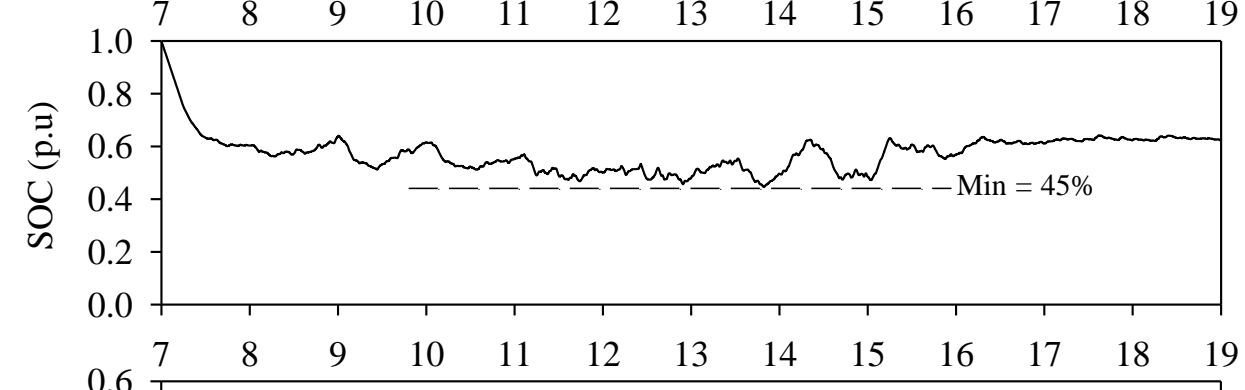

(D)

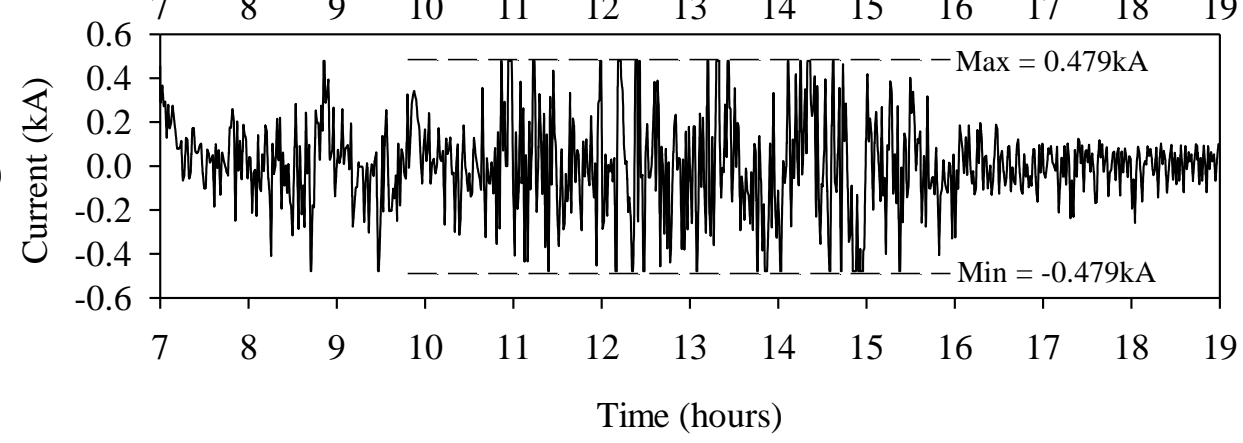

Figure 7. Hourly dispatching performance of the PV/BES system with the BES profiles by using optimal PSO-based SOC-FB control scheme.

Besides that, from Figure 8(B), the results showed the minimum voltage of the BES which was $0.6381 \mathrm{kV}$ that did not exceed the lowest boundary of $0.465 \mathrm{kV}$. As recommended, the voltage of BES should not be $20 \%$ under or over of the rated voltage [000]. Meanwhile, in Figure 8(C), the result showed that during the operation, the SOC of the Li-ion battery did not exceed $45 \%$ compared to SOC of the LA battery in the previous work [22] which was 30\%. This result indicated the depth of discharge of Li-ion and LA battery when mitigating the output power fluctuation of the PV system. Note that by limiting the SOC to be between $30 \%$ and $90 \%$, the deep discharge cycles of battery were minimised in order to extend the lifetime of the battery [20]. From this, it seemed that the lifespan of Li-ion battery was longer than LA battery. Besides that, most LA 
batteries were not recommended to be discharged more than 50\% depth of discharge [11]. Finally, in Figure 8(D), the result illustrated the maximum charge and discharge current profiles that have been limited to $1 \mathrm{x} C_{B E S}$ for safety purposes. From the curve, the charge and discharge current of the Li-ion battery did not exceed $\pm 0.479 \mathrm{kA}$ compared to the charge and discharge current of LA battery in the previous work which was $\pm 0.494 \mathrm{kA}$.

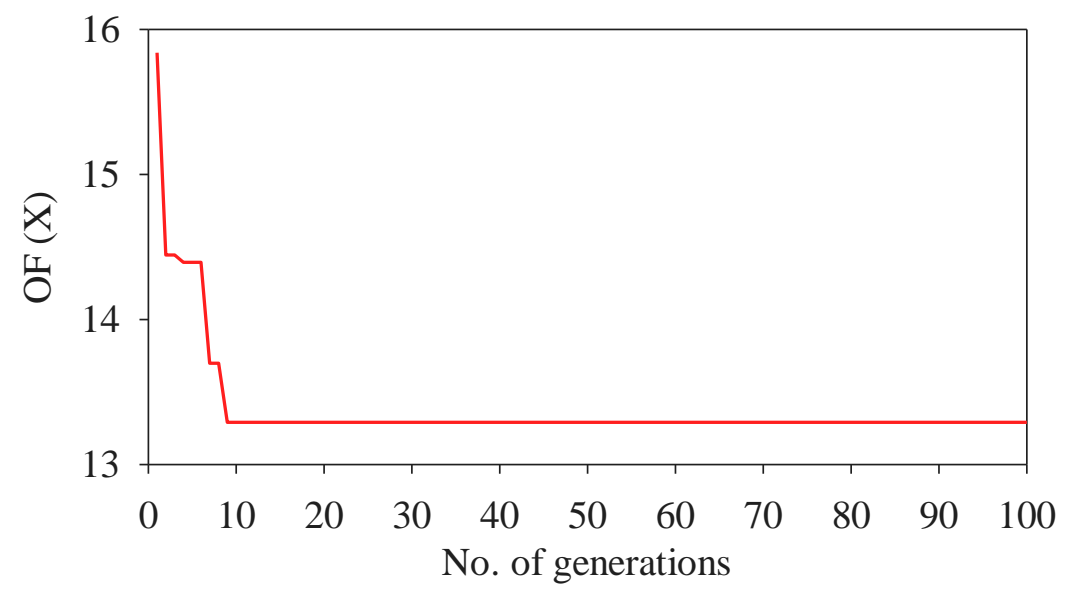

Figure 8. Convergence criteria for PSO-based SOC-FB.

\section{CONCLUSIONS}

This study proposed an improved SOC-FB controller for Li-ion battery with the target of minimising the output power fluctuations of the PV system dispatched on an hourly basis while ensuring the Li-ion BES operational constraints were regulated at the desired ranges. The Li-ion battery model has been successfully developed and validated in MATLAB/Simulink. The simulation was performed for the case of optimisation of SOCFB controller parameters for mitigation of power fluctuation and hourly output power dispatch of PV/BES system using PSO algorithm. From the results, the performances of the proposed controller and the Li-ion battery were quite good, where it was illustrated that the $P_{\text {TOTAL }}$ injected to the grid system followed the desired $P_{S E T}$ perfectly most of the time.

Besides that, the comparison results of the optimisation of SOC-FB parameters showed a better performance of Li-ion battery compared to its LA battery counterpart. The optimal control problem or OF (x) was reduced from 17.07 (LA battery case) to 13.29 (Li-ion battery case). This result indicated that the remaining power fluctuation after mitigation by using Li-ion was less than the remaining power fluctuation after mitigation by using LA battery. Furthermore, the simulation results also show that the optimal size of BES can be reduced up to $1.6 \%$ using Li-ion battery. This indicated the reasonable performance of the Li-ion battery, especially when it comes to mitigating the output power fluctuations of the large scale PV farm. The control strategy was also compromised in that it utilised $64 \%$ of the Li-ion battery capacity in order to extend the lifetime of the BES. Finally, for future studies, it will be very interesting to perform a cost-benefit analysis with the BES system and the authors are planning to present a paper on this subject. 


\section{ACKNOWLEGDEMENTS}

The authors would like to acknowledge Universiti Malaysia Terengganu (UMT) Malaysia and Ministry of Higher Education (MOHE) Malaysia for the financial support of this research. This research is supported by MOHE under the Fundamental Research Grant Scheme (FRGS), Vot No. 59418 (Ref: FRGS/1/2015/TK10/UMT/02/1).

\section{REFERENCES}

[1] Bou-Rabee MA, Sulaiman SA, Choe G, Han D, Saeed T, Marafie S. Characteristics of solar energy radiation on typical summer and winter days in Kuwait. International Journal of Automotive and Mechanical Engineering. 2015;12:2944.

[2] Alam M, Muttaqi K, Sutanto D. Mitigation of rooftop solar PV impacts and evening peak support by managing available capacity of distributed energy storage systems. IEEE transactions on power systems. 2013;28:3874-84.

[3] Li X, Hui D, Lai X. Battery energy storage station (BESS)-based smoothing control of photovoltaic (PV) and wind power generation fluctuations. IEEE Transactions on Sustainable Energy. 2013;4:464-73.

[4] Divya K, Østergaard J. Battery energy storage technology for power systems-An overview. Electric Power Systems Research. 2009;79:511-20.

[5] Dunn B, Kamath H, Tarascon J-M. Electrical energy storage for the grid: a battery of choices. Science. 2011;334:928-35.

[6] Mohd T, Hassan M, Aziz W. Mathematical modeling and simulation of an electric vehicle. Journal of Mechanical Engineering and Sciences. 2015;8:1312-21.

[7] Zhou G, Li F, Cheng H-M. Progress in flexible lithium batteries and future prospects. Energy \& Environmental Science. 2014;7:1307-38.

[8] Julien C, Mauger A, Vijh A, Zaghib K. Springer; 2016.

[9] Albright G, Edie J, Al-Hallaj S. A comparison of lead acid to lithium-ion in stationary storage applications. Published by AllCell Technologies LLC. 2012.

[10] Diouf B, Pode R. Potential of lithium-ion batteries in renewable energy. Renewable Energy. 2015;76:375-80.

[11] Hill CA, Such MC, Chen D, Gonzalez J, Grady WM. Battery energy storage for enabling integration of distributed solar power generation. IEEE Transactions on smart grid. 2012;3:850-7.

[12] Li X, Li Y, Han X, Hui D. Application of fuzzy wavelet transform to smooth wind/PV hybrid power system output with battery energy storage system. Energy Procedia. 2011;12:994-1001.

[13] Li X. Fuzzy adaptive Kalman filter for wind power output smoothing with battery energy storage system. IET Renewable Power Generation. 2012;6:340-7.

[14] Jiang Q, Gong Y, Wang H. A battery energy storage system dual-layer control strategy for mitigating wind farm fluctuations. IEEE transactions on power systems. 2013;28:3263-73.

[15] Alam M, Muttaqi K, Sutanto D. A novel approach for ramp-rate control of solar PV using energy storage to mitigate output fluctuations caused by cloud passing. IEEE Transactions on Energy conversion. 2014;29:507-18. 
[16] Marcos J, de la Parra I, García M, Marroyo L. Control strategies to smooth shortterm power fluctuations in large photovoltaic plants using battery storage systems. Energies. 2014;7:6593-619.

[17] Wang G, Ciobotaru M, Agelidis VG. Power smoothing of large solar PV plant using hybrid energy storage. IEEE Transactions on Sustainable Energy. 2014;5:834-42.

[18] Aly MM, Abdelkarim E, Abdel-Akher M. Mitigation of photovoltaic power generation fluctuations using plug-in hybrid electric vehicles storage batteries. International Transactions on Electrical Energy Systems. 2015;25:3720-37.

[19] Teleke S, Baran ME, Bhattacharya S, Huang AQ. Optimal control of battery energy storage for wind farm dispatching. IEEE Transactions on Energy conversion. 2010;25:787-94.

[20] Teleke S, Baran ME, Bhattacharya S, Huang AQ. Rule-based control of battery energy storage for dispatching intermittent renewable sources. IEEE Transactions on Sustainable Energy. 2010;1:117-24.

[21] Daud MZ, Mohamed A, Hannan M. An improved control method of battery energy storage system for hourly dispatch of photovoltaic power sources. Energy Conversion and Management. 2013;73:256-70.

[22] Daud MZ, Mohamed A, Ibrahim AA, Hannan M. Heuristic optimization of stateof-charge feedback controller parameters for output power dispatch of hybrid photovoltaic/battery energy storage system. Measurement. 2014;49:15-25.

[23] Luo F, Meng K, Dong ZY, Zheng Y, Chen Y, Wong KP. Coordinated operational planning for wind farm with battery energy storage system. IEEE Transactions on Sustainable Energy. 2015;6:253-62.

[24] Bai Q. Analysis of particle swarm optimization algorithm. Computer and information science. 2010;3:180.

[25] Du K-L, Swamy M. Particle swarm optimization: Springer; 2016.

[26] Ishaque K, Salam Z, Amjad M, Mekhilef S. An improved particle swarm optimization (PSO)-based MPPT for PV with reduced steady-state oscillation. IEEE transactions on Power Electronics. 2012;27:3627-38.

[27] Maleki A, Ameri M, Keynia F. Scrutiny of multifarious particle swarm optimization for finding the optimal size of a PV/wind/battery hybrid system. Renewable Energy. 2015;80:552-63.

[28] Chan HL. A new battery model for use with battery energy storage systems and electric vehicles power systems. Power Engineering Society Winter Meeting, 2000 IEEE: IEEE; 2000. p. 470-5.

[29] Tremblay O, Dessaint L-A. Experimental validation of a battery dynamic model for EV applications. World Electric Vehicle Journal. 2009;3:1-10.

[30] Norbakyah J, Fung C, Atiq W, Daud M, Salisa A. An optimal lithium ion battery for plug-in hybrid electric recreational boat in discharging condition. Journal of Mechanical Engineering and Sciences. 2016;10:2363.

[31] Zhang Z, Wang J, Wang X. An improved charging/discharging strategy of lithium batteries considering depreciation cost in day-ahead microgrid scheduling. Energy Conversion and Management. 2015;105:675-84. 